\title{
Strategi Pengembangan Koleksi Reyog Corner Perpustakaan Universitas Muhammadiyah Ponorogo
}

\author{
Yolan Priatna*, Amanda Candra Pratiwi \\ Perpustakaan Universitas Muhammadiyah Ponorogo, Indonesia
}

\section{Article Info}

Received April 1, 2021

Revised April 13, 2021

Accepted April 21, 2021

Keywords

- Collection development

- Library material

- Reyog corner

- Local content

\section{Abstract}

Introduction: Library collection development is a routine activity and must be carried out by all libraries. Even though it has become a routine activity, it is not uncommon for this activity to become difficult to do, as was the case with the Muhammadiyah University of Ponorogo Library which experienced difficulties in developing the Reyog Corner collection, a corner or reading corner containing various collections containing about Reyog and Ponorogo Regency. This study aims to determine the strategy carried out by the Muhammadiyah University of Ponorogo Library in developing a collection for that corner.

Methodology: This study uses a qualitative method with a descriptive approach in conducting research.

Results and Discussion: Based on data analysis and studies conducted, the authors found the results if the obstacles faced in developing collections for Reyog Corner were the lack of library materials containing the study/theme. However, various efforts were made to develop Reyog Corner, including establishing contacts with local governments, direct searches for authors, and independent searches based on subjects through various online shops.

Conclusion: The results of this study are expected to be a reference for readers in developing collections in workplace libraries and private libraries, especially collections that have a certain uniqueness.

\section{Pendahuluan}

Keberadaan buku atau bahan pustaka di dalam sebuah perpustakaan menjadi syarat utama agar perpustakaan dapat berjalan sebagaimana mestinya. Selain syarat, keberadaan buku bagi perpustakaan juga menjadi asset yang paling bisa menarik pemustaka, padahal sebuah koleksi buku membutuhkan perpustakaan agar ide yang ada di dalam sebuah buku dapat diinformasikan kepada publik (Nidawati, 2020). Keberadaan buku yang beredar sangatlah banyak dan seringkali menimbulkan kebingungan bagi pengelola perpustakaan dalam menentukan koleksi mana yang akan disediakan untuk pemustaka, mengingat kebutuhan dari pemustaka tidak selalu sama.

Perpustakaan membutuhkan suatu payung atau landasan dalam menentukan koleksi yang akan dilayankan di perpustakaan mereka. Lazimnya landasan atau payung tersebut dikenal dengan pedoman pengadaan bahan pustaka. Pedoman pengadaan tersebut setidak-tidaknya memuat tentang alat dan cara melakukan seleksi bahan pustaka/buku/koleksi yang akan diadakan, Mengingat tidak mungkin sebuah perpustakaan akan membeli seluruh koleksi yang ada di pasar, meskipun tidak jarang perpustakaan juga mengalami kesulitan ketika mencoba untuk mendapatkan alat seleksi

\footnotetext{
* Corresponding author.

Email address: yolan.priatna@gmail.com (Y. Priatna).
} 
dan koleksi yang termasuk langka. Dalam sebuah perpustakaan, menurut Liauw (Toong Tjiek -Anugraha, 2015) koleksi yang memuat mengenai informasi kearifan localtergolong dalam koleksi local content, yaitu koleksi yang mengandung informasi mengenai entitas local (perorangan, institusi, kegiatan, geografi, dan budaya). Koleksi local content ini berkaitan mengenai kebudayaan dan keadaan lingkungan sosial dari suatu daerah (Rohma Pertiwi \& Yoga Prasetyawan, 2018).

Perpustakaan Universitas Muhammadiyah Ponorogo merupakan salah satu perpustakaan perguruan tinggi yang memiliki sebuah pojok khusus yang berisi konten local Ponorogo serta kesenian Reyog. Reyog telah menjadi identitas dari Kabupaten Ponorogo Jawa Timur, Sehingga Universitas Muhammadiyah Ponorogo memiliki tujuan untuk menjadikan Perpustakaan sebagai salah satu pusat informasi seputar Ponorogo dan juga kesenian Reyog. Namun beberapa kendala yang dihadapi dalam mengembangkan koleksi untuk pojok ini adalah ketersediaan bahan pustaka dan alat seleksi yang beredar sangat terbatas. Menurut Soetminah dalam Fitria (2018) hanya berbagai macam dan jenis serta ketersediaan dari bahan pustaka itu sendiri akan menjadi menjadi tantangan bagi pengelola perpustakaan agar apa yang mereka rencanakan cocok dan memenuhi kebutuhan pemakainya.

Berdasarkan pemaparan permasalahan tersebut, penulis tertarik untuk mengkaji lebih jauh mengenai strategi yang dilakukan oleh Perpustakaan Universitas Muhammadiyah Ponorogo dalam melakukan pengembangan koleksi untuk pojok tersebut. Kajian ini akan menggunakan pendekatan deskriptif untuk menjelaskan bahasan dan analisa terkait pengadaan koleksi yang dilakukan oleh Perpustakaan Universitas Muhammadiyah Ponorogo, khususnya koleksi yang berkaitan dengan pojok Reyog(Reyog Corner).

\section{Tinjauan Pustaka}

\subsection{Pengembangan koleksi}

Pengembangan dan mengembangkan koleksi merupakan salah satu tugas dari sebuah perpustakaan, karena keilmuan yang terekam memerlukan tempat untuk melakukan penyebaran dan penginformasian sehingga kegiatan pengembangan koleksi Reyog Corner ini penting untuk dijalankan oleh sebuah perpustakaan. Merujuk pernyataan dari Perpustakaan Nasional (2020), pengembangan koleksi merupakan rangkaian kegiatan yang bertujuan untuk memperbanyak jumlah koleksi perpustakaan dengan menekankan aspek selektif dan juga evaluasi .

Seleksi yang dimaksudkan dalam konteks pengembangan koleksi ini adalah proses identifikasi pada bahan perpustakaan yang akan menjadi koleksi perpustakaan. Kegiatan ini merupakan kontrol yang dilakukan oleh perpustakaan untuk menyesuaikan anggaran, rencana, serta mencapai tujuan dari perpustakaan itu sendiri, sedangkan evaluasi akan lebih dalam dilakukan oleh perpustakaan karena tahap ini merupakan tahap menganalisa kebutuhan pemustaka di perpustakaan tersebut, sehingga koleksi yang akan dilakukan pengembangan merupakan koleksi yang digunakan dan dibutuhkan (Perpustakaan Nasional, 2018).

Seringkali istilah pengembangan koleksi yang dilakukan oleh perpustakaan dimaknai sebagai kegiatan menambah jumlah koleksi di perpustakaan, sangat berbeda dengan tujuan asli dari kegiatan ini yaitu penambahan item, varian dan tentunya kualitas koleksi yang ada. Pemahaman atau pemaknaan yang sering muncul dari kegiatan pengembangan koleksi ini adalah penambahan jumlah/kuantitas koleksi, padahal kegiatan pengembangan koleksi yang baik adalah pengembangan koleksi yang tidak sebatas menambah kuantitas, melainkan juga menambah kualitas yang ada dari koleksi tersebut. 
Selain itu, hasil dari pengembangan koleksi ini adalah bertambahnya jenis bahan bacaan yang disesuaikan dengan kebutuhan penggunanya, sehingga untuk mencapainya perpustakaan setidak-tidaknya melakukan survei, seleksi dan evaluasi bahan perpustakaan (Rahayuningsih, 2017).

\subsection{Jenis-Jenis Koleksi/Bahan Perpustakaan}

Perpustakaan Nasional Republik Indonesia sebagai induk perpustakaan telah mengklasifikasikan atau membedakan berbagai jenis koleksi yang ada di perpustakaan. Kelima jenis koleksi yang dimaksudkan oleh Perpustakaan Nasional (2020):

a. Bahan perpustakaan tercetak, adalah bahan pustaka yang bersumber dari pemikiran manusia kemudian direkam dalam berbagai bentuk media cetak (kertas)

b. Bahan perpustakaan terekam, adalah bahan pustaka yang bersumber dari pemikiran manusia kemudian direkam dalam berbagai bentuk audio, video maupun audio visual dan membutuhkan alat bantu untuk menggunakannya.

c. Bahan perpustakaan bentuk mikro, adalah bahan pustaka yang bersumber dari hasil alih media koleksi di perpustakaan. Koleksi ini sering ditemukan di perpustakaan yang sudah berumur tua atau di perpustakaan khusus.

d. Bahan perpustakaan kartografi, merupakan bahan pustaka yang spesifik berbentuk gambar dan memiliki ukuran maupun perbandingan tersendiri.

e. Bahan perpustakaan sumber elektronik (e-resources), termasuk dalam bahan pustaka modern. Bahan pustaka ini membutuhkan peran serta teknologi hingga internet untuk mengakses atau menggunakannya.

Berbagai jenis koleksi yang disampaikan oleh Perpusnas ternyata masih terdapat satu jenis koleksi yang belum disebutkan, koleksi yang dimaksudkan adalah koleksi yang mencakup atau yang memuat tentang kearifan lokal.

Koleksi kearifan lokal merupakan koleksi perpustakaan yang mencakup muatan local (local content), koleksi lokal (local collection), serta kearifan lokal (indigenous knowledge). Meskipun tidak semua perpustakaan memiliki koleksi yang bermuatan lokal, penting kiranya untuk menjadikan koleksi lokal sebagai salah satu jenis koleksi penting yang ada di perpustakaan. Mengingat, derasnya perkembangan informasi dalam gaya hidup masyarakat global tidak mampu membuang pengaruh lokal masing-masing yang tertuang dalam bentuk koleksi (cetak \& non cetak) (Laksmi, 2015).

\subsection{Pengadaan Bahan Perpustakaan}

Pada dasarnya pengadaan bahan pustaka yang diakukan oleh perpustakaan merupakan salah satu kegiatan yang bertujuan untuk mengembangkan koleksi yang telah ada sebelumnya agar lebih bervariasi. Tentunya telah diketahui oleh semuanya jika keberadaan koleksi menjadi salah satu parameter dari keberhasilan layanan suatu pepustakaan. Perlu diketahui bahwa pemustaka mempunyai kebutuhan yang berbedabeda, dalam artian perpustakaan umum harus bisa memberikan kebutuhan itu baik tercetak maupun rekaman dengan tepat, cepat dan benar sehingga memberikan kesan yang baik kepada perpustakaan (Anjelina Putri, 2019). Hal ini menjadi salah satu tolok ukur dalam pengadaan koleksi yang relevan. Menurut Evans dalam Andayani (2017), pengadaan atau pengembangan koleksi yang dilakukan oleh perpustakaan memiliki tujuan: (1) untuk mengadakan bahan-bahan secepat mungkin; (2) untuk tetap mempertahankan akurasi dalam prosedur kerja; (3) untuk tetap mempertahankan sistem/proses kerja yang sederhana untuk mendapatkan harga bahan yang lebih murah; dan (4) untuk mengembangkan hubungan kerjasama yang erat dengan vendor. 
Menurut Soeatminah (Soeatminah, 1992) pada dasarnya proses akuisisi/pengadaan merupakan kegiatan yang berkaitan satu dengan lainnya dan dimulai dari penelusuran informasi sebelum pemesanan, hingga menyimpan data/record pengadaan tersebut. Namun banyaknya koleksi yang beredar serta cepatnya laju informasi yang terjadi menjadikan pustakawan harus lebih selektif dalam proses pemilihan buku (Wiranto, 1997).

Selain itu, proses pengadaan atau pengembangan identik dengan pembelian koleksi dalam jumlah yang tidak sedikit. Kendati demikian, ada beberapa cara yang bisa ditempuh perpustakaan melalui metode pemberian hadiah, wakaf, maupun tukar menukar koleksi. Dalam kasus ini perpustakaan akan lebih baik jika telah menyiapkan materi lain yang dapat dijadikan sebagai alat pertukaran, termasuk metode deposit dimana pihak perpustakaan menghimpun koleksi localdari civitas akademika institusi (Purnomo, 2013).

\section{Metode}

Kajian ini menggunakan metode kualitatif dengan pendekatan deskriptif sebagai cara menerangkan masalah yang ada. Penelitian ini tidak mengutamakan besarnya populasi atau sampling bahkan populasi atau samplingnya sangat terbatas. Jika data yang terkumpul sudah mendalam dan bisa menjelaskan kajian yang diteliti, maka tidak perlu mencari sampling lainnya. Sumber referensi dan data yang digunakan berasal dari buku maupun jurnal, serta wawancara dengan pihak yang dianggap penting dan terlibat dalam kegiatan pengembangan koleksi.

\section{Hasil dan Pembahasan}

Perpustakaan Universitas Muhammadiyah Ponorogo menjadi salah satu Perpustakaan Perguruan Tinggi yang telah terakreditasi A oleh Perpustakaan Nasional Republik Indonesia (Perpusnas RI). Tentu berbagai standar yang dimiliki telah sesuai atau lebih dari yang dikehendaki oleh Perpusnas salah satu aspek penting adalah keberadaan koleksi. Tercatat jumlah koleksi Perpustakaan Universitas Muhammadiyah Ponorogo tidak kurang dari 29.437 judul (Ponorogo, 2021) Jumlah yang dihimpun dari seluruh jenis koleksi dan juga area baca di Perpustakaan Universitas Muhammadiyah Ponorogo.

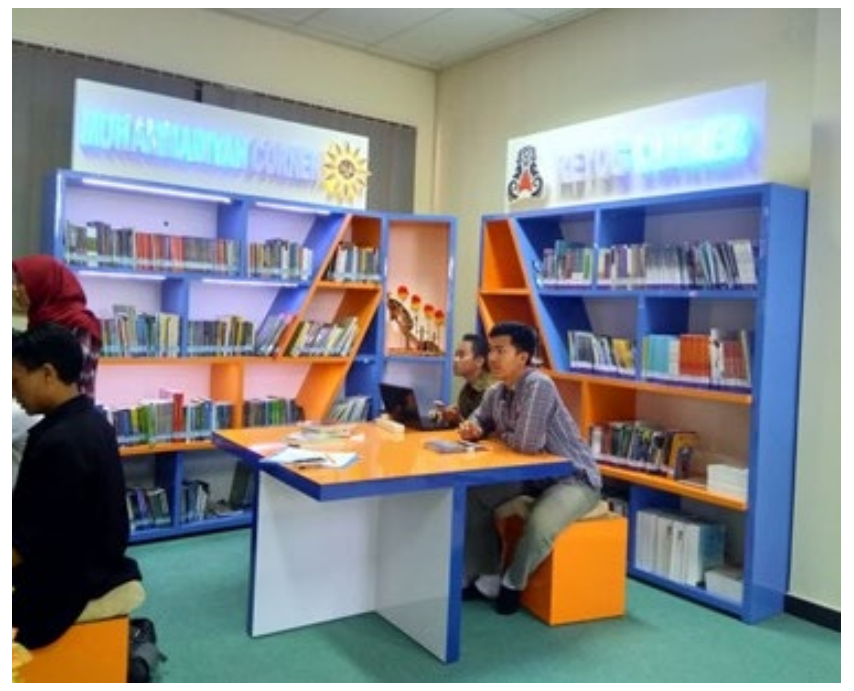

Gambar 1 Reyog Corner Universitas Muhammadiyah Ponorogo (sumber: Perpustakaan Universitas Muhammadiyah Ponorogo yang diolah) 
Beberapa keunikan juga dimiliki oleh Perpustakaan Universitas Muhammadiyah Ponorogo, salah satunya adalah adanya pojok Ponorogo atau yang diberi nama Reyog Corner (lihat Gambar 1). Pojok baca ini merupakan pojok yang didedikasikan untuk Kabupaten Ponorogo serta kesenian Reyog yang telah menjadi identitas Kabupaten Ponorogo. Berbagai koleksi yang ada di Corner ini diantaranya adalah penelitian, buku, artikel ilmiah, alat peraga serta segala hal yang memuat informasi seputar Ponorogo dan Reyog ada di dalamnya.

Beberapa kendala muncul ketika koleksi yang dimiliki mulai "habis" dinikmati pemustaka. Perpustakaan harus segera melakukan penyegaran serta pengembangan di pojok baca ini. Berbagai agenda pengembangan dilakukan agar pojok baca ini tetap memiliki daya tarik bagi pemustaka. Beberapa hal terkait pengembangan koleksi telah dilakukan oleh pengelola perpustakaan. Langkah tersebut adalah:

a. Menjalin kontak dengan pemerintah daerah, khususnya Dinas Pariwisata guna mendapatkan bahan pustaka yang berhubungan dengan Ponorogo maupun Reyog. Kontak dilakukan secara resmi dengan mengirimkan surat kepada pemerintah daerah Kabupaten Ponorogo sebanyak dua kali pada tahun 2018 dan 2021 untuk meminta koleksi kedaerahan yang diterbitkan oleh pemerintah Kabupaten Ponorogo. Hasil dari kegiatan ini perpustakaan mendapatkan beberapa buku yaitu Babad Ponorogo Jilid ke1 hingga ke-7 dan Buku Pesona dan Panduan Wisata Ponorogo sebanyak dua (2) eksemplar untuk setiap edisinya.

b. Pencarian langsung kepada penulis, peneliti maupun stakeholder yang berkaitan dengan Ponorogo maupun Reyog. Agenda ini tidak mudah diakukan karena peneliti yang mengkaji Ponorogo maupun kesenian

c. Reyog sangat terbatas. Perpustakaan bermaksud untuk mendapatkan koleksi yang berasal dari peneliti di luar Universitas Muhammadiyah Ponorogo, akan tetapi karena minimnya peneliti yang berasal dari luar Universitas Muhammadiyah Ponorogo. Perpustakaan hanya dapat menelusur karya yang dihasilkan oleh peneliti Universitas Muhammadiyah Ponorogo sebanyak lima (5) eksemplar (lihat Tabel 1).

Tabel 1 Buku Karya Peneliti Universitas Muhammadiyah Ponorogo (sumber: Perpustakaan Universitas Muhammadiyah Ponorogo yang diolah)

\begin{tabular}{|c|c|c|c|c|c|}
\hline No & Judul & Pengarang & Penerbit & $\begin{array}{l}\text { Tahun } \\
\text { Terbit }\end{array}$ & ISBN \\
\hline 1. & $\begin{array}{l}\text { Seni Reyog Ponorogo; Sejarah, Nilai, } \\
\text { dan Dinamika dari Waktu ke Waktu }\end{array}$ & $\begin{array}{l}\text { Rido } \\
\text { Kurnianto }\end{array}$ & $\begin{array}{l}\text { Buku Litera } \\
\text { Yogyakarta }\end{array}$ & 2017 & $\begin{array}{l}978-602- \\
6751-79-9\end{array}$ \\
\hline 2. & $\begin{array}{l}\text { Obyog Garapan Pelajar Santri : } 4 \\
\text { Variasi Pelestari Seni Reyog Ponorogo }\end{array}$ & $\begin{array}{l}\text { Nurul Iman, } \\
\text { dkk. }\end{array}$ & WADE Group & 2018 & $\begin{array}{l}978-602- \\
5498-97-8\end{array}$ \\
\hline 3. & $\begin{array}{l}\text { Dinamika Tradisi Larungan di } \\
\text { Ponorogo (Perspektif Sosial } \\
\text { Keagamaan) }\end{array}$ & $\begin{array}{l}\text { Rido } \\
\text { Kurnianto }\end{array}$ & CV. Nata Karya & 2017 & $\begin{array}{l}978-602- \\
74711-8-4\end{array}$ \\
\hline 4. & $\begin{array}{l}\text { Membangun Desa melalui Praktik } \\
\text { Pemberdayaan Masyarakat di Desa } \\
\text { Kegusihan Kecamatan Pulung, } \\
\text { Kabupaten Ponorogo }\end{array}$ & $\begin{array}{l}\text { Yusuf Adam } \\
\text { Hilman }\end{array}$ & $\begin{array}{l}\text { Unmuh } \\
\text { Ponorogo Press }\end{array}$ & 2018 & $\begin{array}{l}978-602- \\
0815-99-2\end{array}$ \\
\hline 5. & $\begin{array}{l}\text { Sejarah Adipati dan Bupati Ponorogo } \\
(1496 \text { - 2016) }\end{array}$ & $\begin{array}{l}\text { Alip } \\
\text { Sugianto }\end{array}$ & $\begin{array}{l}\text { Unmuh } \\
\text { Ponorogo Press }\end{array}$ & 2020 & $\begin{array}{l}978-602- \\
0791-71-5\end{array}$ \\
\hline
\end{tabular}

d. Pencarian mandiri berdasarkan subjek. Pencarian ini dilakukan dengan menelusur berbagai sumber informasi yang potensial, yakni pencarian melalui katalog Perpusnas dan pencarian melalui marketplace. Pencarian melalui katalog Perpusnas dilakukan dengan tujuan untuk mendapatkan judul yang berkaitan dengan kesenian Reyog maupun dengan Kabupaten Ponorogo. Setelah judul ditemukan, langkah selanjutnya 
adalah penelusuran di berbagai marketplace dengan kata kunci yang berasal dari hasil penelusuran di katalog Perpusnas. Berbekal daftar judul yang diperoleh dari katalog perpusnas, pencarian dilakukan melalui marketplace yang popular di Indonesia (Bukalapak, Shopee, Tokopedia dan Lazada). Penelusuran yang dilakukan mendapatkan koleksi sejumlah dua puluh lima (25) judul (lihat Tabel 2).

Tabel 2 Hasil Pembelian Koleksi Reyog Corner dari Marketplace Tahun 2021 (sumber: Perpustakaan Universitas Muhammadiyah Ponorogo yang diolah)

\begin{tabular}{|c|c|c|c|}
\hline No & Judul & Pengarang & Jumlah \\
\hline 1. & $\begin{array}{l}\text { Reyog Ponorogo: Media Pelestarian Seni dan Budaya } \\
\text { Indonesia }\end{array}$ & Uswatun Hasanah & 2 \\
\hline 2. & $\begin{array}{l}\text { Reog Ponorogo: Menari di Antara Dominasi dan } \\
\text { Keragaman }\end{array}$ & $\begin{array}{l}\text { Muhammad Zamzam } \\
\text { Fauzannafi }\end{array}$ & 2 \\
\hline 3. & $\begin{array}{l}\text { Modernisasi di Jantung Budaya Jawa: Mangkunegaran } \\
\text { 1896-1944 }\end{array}$ & Wasino & 2 \\
\hline 4. & $\begin{array}{l}\text { Play and Display: Dua Moda Pergelaran Reyog Ponorogo } \\
\text { di Jawa Timur }\end{array}$ & $\begin{array}{l}\text { G.R. Lono Lastoro } \\
\text { Simatupang }\end{array}$ & 2 \\
\hline 5. & Bathik, Identitase Wong Jawa & Djati Prihantono & 2 \\
\hline 6. & Ludruk Jawa Timur dalam Pusaran Zaman & $\begin{array}{l}\text { Prof. Dr. Henri Supriyanto, } \\
\text { M.Hum. }\end{array}$ & 2 \\
\hline 7. & Sejarah Aksara Jawa & Djati Prihantono & 2 \\
\hline 8. & $\begin{array}{l}\text { Sufisme Jawa Transformasi Tasawuf Islam ke Mistik } \\
\text { Jawa }\end{array}$ & Dr. Simuh & 2 \\
\hline 9. & Upacara Perkawinan Adat Jawa & $\begin{array}{l}\text { Upacara Perkawinan Adat } \\
\text { Jawa }\end{array}$ & 1 \\
\hline 10. & Seri Kesenian: Kesenian Reog Ponorogo & $\begin{array}{l}\text { Heni Nurhani \& tita } \\
\text { Nurlelawati }\end{array}$ & 2 \\
\hline 11. & $\begin{array}{l}\text { Komunikasi Nonverbal pada Tari Bujangganong Festival } \\
\text { Reyog Nasional }\end{array}$ & Hamzah Fakhroni & 2 \\
\hline 12. & Imajinasi Identitas Sosial Komunitas Reog Ponorogo & $\begin{array}{l}\text { Muhamad Johan Nasrul } \\
\text { Huda }\end{array}$ & 1 \\
\hline 13. & Mengenal Kesenian Nasional 5: REOG & Kustopo & 2 \\
\hline 14. & $\begin{array}{l}\text { Obyog Garapan Pelajar Santri: } 4 \text { Varian Pelestari Seni } \\
\text { Reyog Ponorogo }\end{array}$ & Nurul Iman dkk & 2 \\
\hline 15. & $\begin{array}{l}\text { Seni Reyog Ponorogo: Sejarah, Nilai dan Dinamika dari } \\
\text { Waktu ke Waktu }\end{array}$ & Rido Kurnianto & 2 \\
\hline 16. & Tentang Reyog Ponorogo & $\begin{array}{l}\text { Heri wijayanto \& Rido } \\
\text { kurnianto }\end{array}$ & 2 \\
\hline 17. & $\begin{array}{l}\text { Pedoman Dasar Kesenian Reyog Ponorogo dalam Pentas } \\
\text { Budaya Bangsa }\end{array}$ & Kab.Ponorogo & 2 \\
\hline 18. & $\begin{array}{l}\text { Makna Simbolik Pakaian Warok pada Kesenian Reyog } \\
\text { Ponorogo }\end{array}$ & Anang Kriswanto BP & 2 \\
\hline 19. & $\begin{array}{l}\text { Pendidikan Karakter Konco Reyog Ponorogo Berbasis } \\
\text { Pendidikan Islam }\end{array}$ & $\begin{array}{l}\text { Rido Kurnianto \& Niken } \\
\text { Lestarini }\end{array}$ & 2 \\
\hline 20. & $\begin{array}{l}\text { Upaya Promosi Festival Reyog sebagai Tarik Wisata di } \\
\text { Kabupaten Ponorogo }\end{array}$ & Gilang Adi Putra & 2 \\
\hline 21. & $\begin{array}{l}\text { Eksistensi Pengrajin Instrumen Seni Reyog di Kabupaten } \\
\text { Ponorogo }\end{array}$ & Galih Dimas Dwi Setyo & 2 \\
\hline 22. & Sejarah Adipati dan Bupati Ponorogo (1496-2016) & Alip Sugianto & 2 \\
\hline 23. & Dinamika Tradisi Larungan di Ponorogo & Rido Kurnianto & 2 \\
\hline 24. & Batik Reyog: Potential of Creative Industry in Ponorogo & JJ Sarungu, dkk & 2 \\
\hline 25. & Reog Ponorogo: Komunikasi, Religi dan Budaya & Agus Triyono, dkk & 2 \\
\hline
\end{tabular}

Sebelum pencarian tersebut, Perpustakaan Universitas Muhammadiyah Ponorogo telah melakukan berbagai cara untuk mendapatkan panduan penelusuran. Cara yang dimaksudkan di antaranya adalah survei kepuasan pemustaka serta usulan bahan pustaka oleh pemustaka. Menurut penuturan staf bagian pengadaan dan akuisisi perpustakaan Universitas Muhammadiyah Ponorogo, proses pengembangan koleksi yang dilakukan 
sebenarnya tidak jauh berbeda dengan pengadaan koleksi lainnya. Hanya saja, tantangan yang dihadapi lebih banyak daripada pengadaan koleksi umum lainnya.

"Ya sebenernya proses pengadaan dan pengembangannya sama seperti lainnya mas. Cuma effort untuk mendapatkannya saja yang tidak mudah. Terlebih minimnya peneliti seputar kesenian Reyog maupun yang berkaitan semakin menambah tingkat kesulitannya. Apalagi jika mengandalkan instansi pemerintah yang sangat lambat merespon dari kita. Sehingga kita lebih memilih melakukan penelusuran secara mandiri" (wawancara AS, 2021)

Meskipun demikian, perpustakaan Universitas Muhammadiyah Ponorogo tetap berusaha melakukan penelusuran mengenai subjek tersebut melalui marketplace, dengan harapan koleksi yang di inginkan dapat diadakan ketika masa pengadaan pada bulan Mei telah tiba (lihat Tabel 3 dan Tabel 4).

Tabel 3 Hasil Rekomendasi Pembelian Koleksi Reyog Tahun 2021 (sumber: Perpustakaan Universitas Muhammadiyah Ponorogo yang diolah)

\begin{tabular}{|c|c|c|c|c|c|}
\hline No & Judul Buku & Pengarang & Tahun & Penerbit & Marketplace \\
\hline 1. & $\begin{array}{l}\text { Reog Ponorogo Menari di Antara } \\
\text { Dominasi dan Keragaman }\end{array}$ & $\begin{array}{l}\text { Muhammad } \\
\text { Zamzam Fauzannafi }\end{array}$ & 2005 & Kepel Press & Bukalapak \\
\hline 2. & $\begin{array}{l}\text { Imajinasi Identitas Sosial Komunitas } \\
\text { Reog Ponorogo }\end{array}$ & $\begin{array}{l}\text { Muhammad Johan } \\
\text { Nasrul Huda }\end{array}$ & 2011 & $\begin{array}{l}\text { Perpustakaan } \\
\text { Nasional }\end{array}$ & Bukalapak \\
\hline 3. & $\begin{array}{l}\text { Play and Display: Dua Moda } \\
\text { Pergelaran Reyog Ponorogo di Jawa } \\
\text { Timur }\end{array}$ & Lono Simatupang & 2019 & $\begin{array}{l}\text { Universitas Gajah } \\
\text { Mada Press }\end{array}$ & Shopee \\
\hline 4. & $\begin{array}{l}\text { Reog Ponorogo: Komunikasi, Religi } \\
\text { dan Budaya }\end{array}$ & $\begin{array}{l}\text { Abrar Adhani dan } \\
\text { Sulthon }\end{array}$ & 2017 & Buku Litera & Tokopedia \\
\hline 5. & $\begin{array}{l}\text { Seni Reyog Ponorogo: Sejarah, Nilai, } \\
\text { dan Dinamika dari Waktu ke Waktu }\end{array}$ & Rido Kurnianto & 2017 & - & Tokopedia \\
\hline 6. & Reog Ponorogo & Herry Lisbijanto & 2003 & Graha Ilmu & Tokopedia \\
\hline 7. & $\begin{array}{l}\text { Raden Bathoro Katong Bapak E Wong } \\
\text { Ponorogo }\end{array}$ & Muh Fajar Pramono & 2006 & $\begin{array}{l}\text { Lembaga Penelitian } \\
\text { Pemberdayaan } \\
\text { Birokrasi dan } \\
\text { Masyrakat } \\
\text { Ponorogo }\end{array}$ & Shopee \\
\hline 8. & $\begin{array}{l}\text { Seri Kesenian: Kesenian Reog } \\
\text { Ponorogo }\end{array}$ & $\begin{array}{l}\text { Heri Nurhani dan } \\
\text { Tita Nurlelawati }\end{array}$ & - & - & Tokopedia \\
\hline 9. & Mengenal Kesenian Nasional Reog & - & - & - & Bukalapak \\
\hline 10. & Retorika Seni Berbicara & Aristoteles & - & - & Shopee \\
\hline 11. & Seni Tari dan Tradisi yang Berubah & Hasnah SY & - & - & Shopee \\
\hline 12. & $\begin{array}{l}\text { Pengetahuan Elementer Tari dan } \\
\text { Beberapa Masalah Tari }\end{array}$ & - & 1986 & $\begin{array}{l}\text { Direktorat } \\
\text { Kesenian }\end{array}$ & Shopee \\
\hline 13. & Mengenal Seni Tari & Weni R & 2009 & Mediantara & Tokopedia \\
\hline 14. & $\begin{array}{l}\text { Ludruk Jawa Timur dalam Pusaran } \\
\text { Zaman }\end{array}$ & Henry Supriyanto & - & - & Shopee \\
\hline 15. & Ludruk Kedua & $\begin{array}{l}\text { Dadang Ari } \\
\text { Murtono }\end{array}$ & & Basabasi & Tokopedia \\
\hline 16. & $\begin{array}{l}\text { Postkolonial Pada Lakon Ludruk Jawa } \\
\text { Timur }\end{array}$ & $\begin{array}{l}\text { Hendricus } \\
\text { Supriyanto }\end{array}$ & - & - & Shopee \\
\hline 17. & Tari Gambyong Tayub & Purwadi & - & $\begin{array}{l}\text { Pustaka Utama } \\
\text { Barokah }\end{array}$ & Bukalapak \\
\hline 18. & $\begin{array}{l}\text { Srinthil 12: Penari Gandrung dan } \\
\text { Gerak Sosial Banyuwangi }\end{array}$ & Desantara & 2007 & - & Tokopedia \\
\hline 19. & $\begin{array}{l}\text { Tari-Tarian Nusantara (Berbagai Seni } \\
\text { Tari) }\end{array}$ & $\begin{array}{l}\text { Nurul Hasanah RA } \\
\text { dan Anila Safitri }\end{array}$ & - & Azka Press & Tokopedia \\
\hline 20. & Gandrung Banyuwangi & - & - & Depdikbud & Tokopedia \\
\hline 21. & Srimpi 1925 & Hermanu & 2012 & Bentara Budaya & Bukalapak \\
\hline 22. & Ensiklopedia Tarian Nusantara & Keen Achroni & 2018 & $\begin{array}{l}\text { Trans Idea } \\
\text { Publishing }\end{array}$ & Shopee \\
\hline 23. & Ensiklopedia Tari-Tarian Nusantara & Rizky Utami & - & Angkasa & Tokopedia \\
\hline
\end{tabular}




\begin{tabular}{|c|c|c|c|c|c|}
\hline No & Judul Buku & Pengarang & Tahun & Penerbit & Marketplace \\
\hline 24. & $\begin{array}{l}\text { Ensiklopedia Seni Budaya: Rumah } \\
\text { Adat, Suku, dan Tarian Nusantara }\end{array}$ & Muhammad Noor & - & - & Tokopedia \\
\hline 25. & $\begin{array}{l}\text { Masyarakat Adat dan Kedaulatan } \\
\text { Pangan }\end{array}$ & Ahmad Arif & 2020 & $\begin{array}{l}\text { Kepustakaan } \\
\text { Populer Gramedia }\end{array}$ & Tokopedia \\
\hline 26. & Adat Budaya Resam Melayu Langkat & Zainal Arifin & - & Penerbit Mitra & Blibli \\
\hline 27. & $\begin{array}{l}\text { Ensiklopedia Adat-Istiadat Budaya } \\
\text { Jawa }\end{array}$ & Purwadi & - & Panji Pustaka & Tokopedia \\
\hline 28. & Adat Istiadat Sunda & Hasan Mustapa & - & - & Tokopedia \\
\hline 29. & Kecak dari Ritual ke Teatrikal & I Wayan Dibia & - & - & Lazada \\
\hline 30. & Mengenal Tari Kecak & Anandita F.P & - & - & Tokopedia \\
\hline 31. & The Massage of Dalem Sidhkarya & $\begin{array}{l}\text { Putera Eka } \\
\text { Santhosa }\end{array}$ & - & - & Tokopedia \\
\hline 32. & Asal Muasal Zaipin Melayu & Tomi & - & - & Blibli \\
\hline 33. & $\begin{array}{l}\text { Saman: Tari Tangan Seribu dari } \\
\text { Dataran Tinggi Gayo }\end{array}$ & Isma Tantawi & 2020 & - & Tokopedia \\
\hline 34. & $\begin{array}{l}\text { Tradisi Adat Jawa: Menggali Kearifan } \\
\text { Lokal Tradisi Sedekah Bumi } \\
\text { Masyarakat Banyumas }\end{array}$ & - & - & - & Tokopedia \\
\hline 35. & Ensiklopedi Kebudayaan Jawa & Purwadi & - & Panji Pustaka & Tokopedia \\
\hline 36. & Kamus Basa Jawa Bausastra Jawa & $\begin{array}{l}\text { Tim Penulis Balai } \\
\text { Bahasa Yogyakarta }\end{array}$ & - & - & Tokopedia \\
\hline 37. & $\begin{array}{l}\text { Mengapa G30S/PKI Gagal? Suatu } \\
\text { Analisis }\end{array}$ & $\begin{array}{l}\text { Mayjen (Purn) } \\
\text { Samsudin }\end{array}$ & 2004 & $\begin{array}{l}\text { Yayasan Pustaka } \\
\text { Obor Indonesia }\end{array}$ & Tokopedia \\
\hline 38. & $\begin{array}{l}\text { A Flood on Java: Tiga Lakon Tentang } \\
\text { Pandemi }\end{array}$ & Seno Joko Suyono & - & - & Tokopedia \\
\hline 39. & Upacara Perkawinan Adat Jawa & $\begin{array}{l}\text { Thomas Wiyasa } \\
\text { Bratawidjaja }\end{array}$ & - & - & Tokopedia \\
\hline 40. & Sajen dan Ritual Orang Jawa & Wahyana Giri MC & - & - & Tokopedia \\
\hline 41. & $\begin{array}{l}\text { Upacara Perkawinan Adat Batak } \\
\text { Dengan Pemberian Marga }\end{array}$ & $\begin{array}{l}\text { Bien Pasaribu dan } \\
\text { Edison P Hutauruk }\end{array}$ & - & Papas Sinar Sinanti & Tokopedia \\
\hline 42. & $\begin{array}{l}\text { Selayang Pandang Langkah Diplomasi } \\
\text { Kerajaan Aceh }\end{array}$ & Nur El Ibrahimy & - & - & Tokopedia \\
\hline 43. & Sejarah Gaib Tanah Jawa & C. W. Leadbeater & - & - & Tokopedia \\
\hline 44. & Kaladesa: Awal Sejarah Nusantara & - & - & $\begin{array}{l}\text { Wedatama Widya } \\
\text { Sastra }\end{array}$ & Tokopedia \\
\hline 45. & Pelayaran dan Perniagaan Nusantara & Adrian B Lapian & - & - & Tokopedia \\
\hline 46. & Tentang Tari & $\begin{array}{l}\text { Bagong } \\
\text { Kussudiardjo }\end{array}$ & - & - & Tokopedia \\
\hline 47. & $\begin{array}{l}\text { Kearifan Lingkungan dalam Perpesktif } \\
\text { Budaya Jawa }\end{array}$ & Nasruddin Amshar & - & $\begin{array}{l}\text { Yayasan Obor } \\
\text { Indonesia }\end{array}$ & Bukalapak \\
\hline 48. & $\begin{array}{l}\text { Fiqh Adat: Tradisi Masyarakat dalam } \\
\text { Pandangan Fiqh }\end{array}$ & - & - & - & Bukalapak \\
\hline 49. & Tata Upacara Pinangaten Adat Jawa & Khanifatul & - & - & Shopee \\
\hline 50. & $\begin{array}{l}\text { Tanaman Kultural dalam Perspektif } \\
\text { Adat Jawa }\end{array}$ & Purnomo & - & - & Tokopedia \\
\hline
\end{tabular}

Tabel 4 Perbandingan Rekomendasi Koleksi Reyog di Marketplace Tahun 2021 (sumber: Perpustakaan Universitas Muhammadiyah Ponorogo yang diolah)

\begin{tabular}{llllll}
\hline Marketplace & Bukalapak & Tokopedia & Shopee & Bibli & Lazada \\
\hline Jumlah & 6 & 33 & 9 & 1 & 1 \\
\hline
\end{tabular}

\section{Kesimpulan}

Secara keseluruhan, proses pengembangan koleksi Perpustakaan Universitas Muhammadiyah Ponorogo telah melakukan prosedur seperti apa yang disampaikan oleh Soeatminah (Soeatminah, 1992). Proses penyeleksian, penelusuran hingga mendapatkan koleksi telah dilakukan dengan baik, meskipun tidak semua upaya membuahkan hasil seperti apa yang diharapkan karena adanya kendala yang berasal dari minimnya pengarang/peneliti yang mengangkat tema seputar kesenian Reyog maupun Kabupaten Ponorogo, lambatnya respon instansi pemerintah yang membidangi kesenian Reyog serta 
terbatasnya koleksi yang memuat informasi seputar kesenian Reyog maupun Kabupaten Ponorogo.

Berdasarkan pemaparan yang telah dilakukan, penulis berharap agar kuantitas dan kualitas peneliti local semakin banyak dan pemerintah memberikan dukungan penuh melalui kegiatan kepakaran maupun dukungan melalui layanan. Selain mempermudah dalam proses pelestarian, budaya atau kebudayaan yang dituliskan akan terus dikenang dan terus lestari karena informasi tidak berhenti pada satu generasi.

Daftar Pustaka

Andayani, S. (2017). Konstribusi Tokoh dalam Dunia Perpustakaan: Analisis Pemikiran G. Edward Evans tentang Pengembangan Koleksi. In LIBRIA (Vol. 9, Issue 1). https://www.jurnal.ar-raniry.ac.id/index.php/libria/article/view/1691

Anjelina Putri, C. (2019). Pengadaan Koleksi Muatan Lokal "Local Content" sebagai Upaya Pelestarian Budaya Daerah di Dinas Kearsipan dan Perpustakaan Provinsi Sumatera Barat. IImu Informasi Perpustakaan Dan Kearsipan, 8(1), 73-81. http://ejournal.unp.ac.id/index.php/iipk/article/view/107298

Fitria, A. (2018). Persepsi Mahasiswa Jurusan IImu Perpustakaan Terhadap Sistem Temu Kembali Informasi Pada Aplikasi Slims (Senayan Library Management System) Di Pusat Perpustakaan Universitas Islam Negeri Sulthan Thaha Saifuddin Jambi [Universitas Islam Negeri Sulthan Thaha Saifuddin]. http://repository.uinjambi.ac.id/806/

Laksmi, M. A. (2015). Pengembangan Koleksi. In pustaka.ut.ac.id. https://www.pustaka.ut.ac.id/lib/wp-content/uploads/pdfmk/PUST4102-M1.pdf

Nidawati, H. (2020). Pengembangan Koleksi Perpustakaan. http://idr.uinantasari.ac.id/15009/

Perpustakaan Nasional. (2018). Bahan Ajar Pendidikan dan Pelatihan Pengenalan Pengelolaan Perpustakaan. Perpustakaan Nasional.

Perpustakaan Nasional. (2020). Bahan Ajar Pendidikan dan Pelatihan Teknis Pengelolaan Perpustakaan Inpassing (Buku 1). Pusdiklat Perpusnas RI.

Ponorogo, P. U. M. (2021). Katalog Online Library Umpo.

Purnomo, P. (2013). Pengembangan Koleksi Kearifan Lokal (Local Content) Uin Syarif Hidayatullah Jakarta: Peluang Dan Tantangan. Al-Maktabah, 12(1). http://journal.uinjkt.ac.id/index.php/al-maktabah/article/view/1591

Rahayuningsih, F. (2017). Pengelolaan perpustakaan (1st ed.). Graha Ilmu. http://repo.iainbatusangkar.ac.id/xmlui/handle/123456789/10152

Rohma Pertiwi, A., \& Yoga Prasetyawan, Y. (2018). Pengelolaan Koleksi Local Content Sebagai Upaya Pelestarian Kearifan Lokal Di Dinas Perpustakaan Dan Kearsipan Kota Salatiga. Jurnal IImu Perpustakaan, 73), 241-250. https://ejournal3.undip.ac.id/index.php/jip/article/viewFile/22937/20974

Soeatminah, P. (1992). Kepustakawanan dan Perpustakaan. Penerbit Kanisius.

Toong Tjiek -Anugraha, L. (2015). Desa Informasi: Local Content Global Reach. Seminar of the International Council on Archives, East Lansing. 6-9 September. https://www.researchgate.net/publication/228459523

Wiranto, F. . (Ed.). (1997). Perpustakaan Menjawab Tantangan Zaman. Universitas Katolik Soegijopranoto. 